\title{
Protein Tyrosine Kinase Activities of the Epidermal Growth Factor Receptor and ErbB Proteins: Correlation of Oncogenic Activation with Altered Kinetics
}

\author{
N. NAIR, ${ }^{1}$ R. J. DAVIS, ${ }^{2}$ AND H. L. ROBINSON ${ }^{1 *}$ \\ Department of Pathology ${ }^{1}$ and Howard Hughes Medical Institute, ${ }^{2}$ University of \\ Massachusetts Medical Center, Worcester, Massachusetts 01655
}

Received 14 November 1991/Accepted 5 February 1992

\begin{abstract}
We have compared the protein tyrosine kinase activities of the chicken epidermal growth factor receptor (chEGFR) and three ErbB proteins to learn whether cancer-activating mutations affect the kinetics of kinase activity. In immune complex assays performed in the presence of $15 \mathrm{mM} \mathrm{Mn}^{2+}$, ErbB proteins and the chEGFR exhibited highly reproducible tyrosine kinase activity. Under these conditions, the ErbB and chEGFR proteins had similar apparent $K_{m}\left[K_{m}(\right.$ app $\left.)\right]$ values for ATP. The ErbB proteins appeared to be activated, as they had at least 3-fold-higher relative $V_{\max }(\operatorname{app})$ for autophosphorylation and $\sim 2$-fold higher relative $V_{\max }(a p p)$ for the phosphorylation of the exogenous substrate TK6 (a bacterially expressed fusion protein containing the C-terminal domain of the human EGFR). The ErbB kinases had both higher $K_{m}($ app) and higher $V_{\max }($ app) for the phosphorylation of the exogenous substrate TK6 than did the chEGFR. The ratios of the $V_{\max }\left(\right.$ app) to the $K_{m}($ app) for TK6 phosphorylation suggested that the ErbB proteins had lower catalytic efficiencies for the exogenous substrate than did the chEGFR. The three tested ErbB proteins had cytoplasmic domain mutations that conferred distinctive disease potentials. These mutations did not affect the kinetics for the phosphorylation of the exogenous substrate TK6. Two of the ErbB proteins contained all of the sites used for autophosphorylation. In these, a mutation that broadened oncogenic potential to endothelial cells caused an additional increase in $V_{\max }($ app) for autophosphorylation. Thus, mutations that change the EGFR into an ErbB oncogene cause multiple changes in the kinetics of protein tyrosine kinase activity.
\end{abstract}

The v-erbB oncogenes of avian erythroblastosis viruses (AEV) arise by recombination of an avian leukosis virus with host sequences encoding the transmembrane and cytoplasmic domains of the chicken epidermal growth factor receptor (chEGFR). The EGFR consists of four functional domains: an extracellular epidermal growth factor (EGF)-binding $\mathbf{N}$ terminus, a short transmembrane domain, a tyrosine kinase domain, and a $\mathrm{C}$ terminal domain containing the major sites of EGF-stimulated autophosphorylation (for a review, see reference 28). Thirty to forty independent isolates of AEV have been identified $(2,5,11,18,22)$. The EGF-binding domain is truncated in all of these isolates. Many also contain point mutations, truncations, or internal deletions in the cytoplasmic domain of the receptor. These mutations determine differences in the potential to induce erythroblastosis, angiosarcoma, hemangioma, or fibrosarcoma $(7,21$, $22,24,27)$.

The tyrosine kinase activity of the EGFR is required for its mitogenic activity (28). Analysis of the transformation potential of a series of linker insertion mutations in ErbB suggests that kinase activity is required for transformation (20). As ErbB lacks the EGF-binding domain, its kinase activity has been hypothesized to cause transformation by virtue of its activity being ligand independent. This study was undertaken to determine whether truncation of the ligand-binding domain affected the kinetics as well as the ligand dependence of kinase activity.

Prior studies with ErbB proteins have demonstrated tyrosine kinase activity for autophosphorylation and the phosphorylation of synthetic peptides $(3,8,9,10,15)$. Prior

\footnotetext{
* Corresponding author.
}

studies have also tested whether cytoplasmic domain mutations that broaden the transforming potential of ErbB affect in vivo levels of autophosphorylation. These tests suggested that about one-half of activating mutations (three of six tested) would be associated with increased levels of in vivo autophosphorylation $(24,25)$.

Constructed proteins have also been used to analyze the effects of different domains of the EGFR on tyrosine kinase activity. Assays using the human EGFR and 66- and 42-kDa forms of the cytoplasmic domain have revealed many differences in kinetic activities $(14,29)$. Millimolar levels of the divalent cation $\mathrm{Mn}^{2+}$ activate the activity of the holoreceptor and support the activity of the fragments. In the presence of similar levels of $\mathrm{Mg}^{2+}$, the activity of the holoreceptor is EGF dependent and the fragments are largely inactive. The relative activities of the holoreceptor and its fragments also depend on salt conditions $(14,29)$. In the presence of $\mathrm{Mn}^{2+}$ and low salt, the $42-\mathrm{kDa}$ fragment and holoreceptor have similar activities, whereas the $66-\mathrm{kDa}$ fragment has a lower specific activity. In the presence of $\mathrm{Mn}^{2+}$ and high salt $(1 \mathrm{M}$ $\mathrm{NH}_{4} \mathrm{SO}_{4}$ ), the receptor becomes EGF dependent, the 42$\mathrm{kDa}$ fragment is inactive, and the $66-\mathrm{kDa}$ form is more active than the EGF-stimulated holoreceptor.

To test for a potential role of the kinetics of kinase activity in oncogenic potential, the kinase activities of three ErbB proteins were compared with that of the chEGFR. Each of the ErbB proteins represented approximately $80-$ to $85-\mathrm{kDa}$ glycoproteins that contain the transmembrane as well as cytoplasmic domains of the chEGFR. The first, AEV-5005 ErbB, represented a nonmutated, C-terminal complete ErbB that causes only erythroblastosis $(7,27)$. The second, AAV5005 ErbB, served as an example of an ErbB that transforms erythroid as well as endothelial cells $(7,27)$. The ability of 


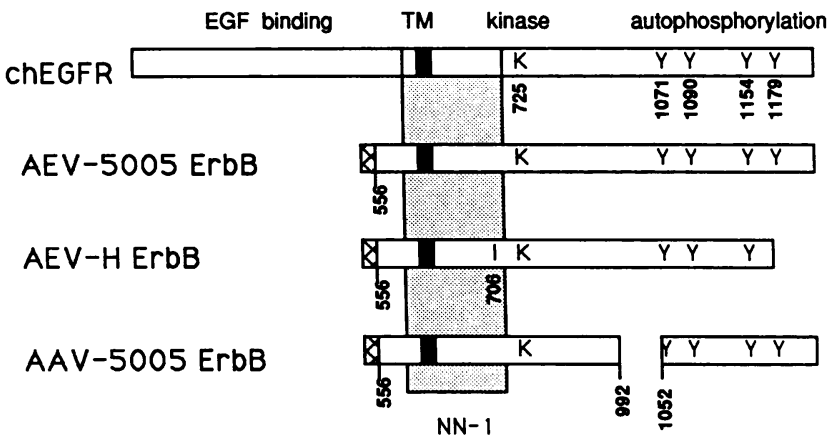

FIG. 1. Schematic representations of the chEGFR and ErbB proteins. Numbers designate amino acid positions in the chEGFR (17). Tyrosine residues that are homologs of the sites of autophosphorylation in the human EGFR and the lysine that is the homolog of the site for ATP binding are designated $\mathrm{Y}$ and $\mathrm{K}$, respectively. An activating mutation of valine 706 to isoleucine in the kinase domain of AEV-H ErbB is designated I (24). $\rtimes$. sequence from the avian leukosis virus Gag protein; $\square$, sequence against which the NN-1 antibody is directed; TM, transmembrane domain.

this ErbB to transform endothelial cells is determined by an in-frame deletion in its C-terminal domain (27). The third, AEV-H ErbB, was used to represent an erythroblast- as well as fibroblast-transforming ErbB protein (30). The AEV-H ErbB has an activating point mutation in the ATP-binding region of its kinase domain as well as a $C$-terminal truncation $(21,24)$. Our results indicate that each of the ErbB proteins differed from the chEGFR in the kinetics of its tyrosine kinase activities. We suggest that these kinetic differences contribute to the transforming potential of ErbB proteins.

\section{MATERIALS AND METHODS}

EGFR and ErbB glycoproteins. Figure 1 presents schematics of the chEGFR and ErbB proteins used in the study. The chEGFR was obtained from a murine EGFR-negative chEGFR-expressing clone of NIH 3T3 cells (17) and earlypassage chicken embryo fibroblasts (CEF). These are referred to as chEGFR (NIH 3T3) and chEGFR (CEF), respectively. The ErbBs of AEV-5005 and AAV-5005 were expressed by plasmid srE- and srE/A-transfected clones (27) of a transformed quail cell line, QT6 (19). srE encodes the ErbB gene of AEV-5005. srE/A represents a recombinant of srE containing the internal deletion of the ErbB of AAV5005 (27). The ErbB of AEV-H was expressed in QT6 cells by a spreading infection initiated by cotransfection of molecular clones of AEV-H (pAE 7.7) (30) and a helper virus, pRAV-10R (23). Nontransfected QT6 cells were used as a source of the quail EGFR (quEGFR).

Antisera. Immunoprecipitations were done with NN-1, a polyclonal rabbit serum raised against the $\mathrm{N}$ terminus of ErbB (Fig. 1) by using a bacterially expressed TrpE fusion protein. A 463-bp region at the $5^{\prime}$ end of the v-erbB of AEV-H (ApaI-to-BamHI fragment from pAE7.7) was cloned into the pATH10 vector (4) and expressed in Escherichia coli DH1 as a $54-\mathrm{kDa}$ protein. Bands containing the fusion protein were cut from sodium dodecyl sulfate (SDS)-polyacrylamide gels and homogenized in the presence of Freund's complete adjuvant. Homogenates containing $\sim 300 \mu \mathrm{g}$ of the fusion protein $(\sim 1 \mathrm{ml})$ were injected into the thigh muscles of New Zealand White rabbits. Four weeks later, rabbits were boosted by intramuscular inoculation with $-100 \mu \mathrm{g}$ of the fusion protein in the presence of Freund incomplete adjuvant.
High-titered sera were obtained 2 weeks following the first boost as well as 2 weeks following each of three subsequent boosts. A monoclonal antibody, 20.3.6, raised by M. Hayman (State University of New York, Stony Brook) against the kinase region of the ErbB gene of AEV-R was used for protein blot analyses. A mouse monoclonal antibody, PY20 (ICN, Costa Mesa, Calif.), was used to detect phosphotyrosine.

In vitro kinase assay. A total of $10 \times 10^{6}$ to $20 \times 10^{6}$ cells expressing the chEGFR or ErbB were solubilized per $\mathrm{ml}$ of ice-cold lysis buffer (50 mM N-2-hydroxyethylpiperazine$N^{\prime}$-2-ethanesulfonic acid [HEPES; $\mathrm{pH} 7.4$ ], $500 \mathrm{mM} \mathrm{NaCl}, 5$ mM EGTA, $1 \%$ Triton X-100, $10 \%$ glycerol, $50 \mathrm{mM} \mathrm{NaF}$, $200 \mu \mathrm{M}$ sodium orthovanadate, $10 \mu \mathrm{g}$ of leupeptin per $\mathrm{ml}$ ). Lysates were placed on ice and clarified by centrifugation at $4^{\circ} \mathrm{C}$ for $20 \mathrm{~min}$ at $16,000 \mathrm{rpm}$ in the SS34 rotor in a Sorvall RC5B centrifuge. For each point of a kinase assay, $1 \mathrm{ml}$ of supernatant was immunoprecipitated with $25 \mu$ l (packed volume) of protein A-Sepharose CLAB beads (Sigma, St. Louis, Mo.) that had been preincubated at room temperature for 40 min with $7 \mu l$ of NN-1 and $63 \mu l$ of lysis buffer and then washed four times with lysis buffer. Immunoprecipitations were done on a rocker in a cold room $\left(5\right.$ to $\left.7^{\circ} \mathrm{C}\right)$ for $90 \mathrm{~min}$. Beads were then washed two times with lysis buffer and two times with HNTG (50 mM HEPES [pH 7.4], $150 \mathrm{mM} \mathrm{NaCl}$, $0.1 \%$ Triton, $10 \%$ glycerol, $50 \mathrm{mM} \mathrm{NaF}, 200 \mu \mathrm{M}$ sodium orthovanadate). Kinase reactions were run in $50 \mu \mathrm{l}$ of reaction buffer (HNTG supplemented with $15 \mathrm{mM} \mathrm{MnCl} \mathrm{M}_{2}$ and $1 \mathrm{mM}$ dithiothreitol) containing from 0.25 to $125 \mu \mathrm{M}$ ATP (Pharmacia, Piscataway, N.J.) and from 0 to $40 \mu \mathrm{M}$ TK6 (an exogenous substrate; see below). ATP was adjusted to a specific activity (s.a.) of 5 to $15 \mu \mathrm{Ci} / \mathrm{nmol}$ with $\left[\gamma_{-}{ }^{32} \mathrm{P}\right]$ ATP (Amersham, Arlington Heights, Ill.). Reaction mixtures were incubated at $25^{\circ} \mathrm{C}$ for $70 \mathrm{~s}$ for studies on autophosphorylation and at $25^{\circ} \mathrm{C}$ for $10 \mathrm{~min}$ for studies on the phosphorylation of exogenous substrates (see Results for linearity of reactions). Reactions were stopped by the addition of an equal volume of $2 \times$ SDS-sample buffer (16). The samples were boiled for $2 \mathrm{~min}$ prior to SDS-polyacrylamide gel electrophoresis (SDS-PAGE) analysis. Incorporated ${ }^{32} \mathrm{P}$ was visualized by autoradiography and quantitated by Betascope analysis (Betascope 603; Betagen, Waltham, Mass.) of dried gels. Kinetic parameters were obtained by using the Michaelis-Menten analyses in the computer program ENZFITTER (Elsevier-Biosoft).

Exogenous substrate. TK6, a fusion of the glutathione $S$-transferase protein with the C-terminal region of the human EGFR, was used as an exogenous substrate (14). This protein was expressed by pGEX-TK6-transformed BL21 bacterial cells and purified by using the reported protocol with the modification of the use of a Sephadex G-25 PD 10 gel filtration column (Pharmacia) to remove residual glutathione from samples. The purity and integrity of TK6 were verified by SDS-PAGE, and the concentration was determined using the Bradford assay (Bio-Rad, Richmond, Calif.) with a bovine serum albumin (BSA) standard.

Western immunoblots. Proteins were electroblotted on nitrocellulose paper (26), using $0.3 \%$ Trizma base-1.5\% glycine- $0.037 \%$ SDS-20\% methanol as the transfer buffer. The rat monoclonal antibody 20.3.6 (see above) was used to detect EGFR and ErbB proteins, rabbit anti-rat immunoglobulin G (Organon Teknika, Durham, N.C.) was used to detect the bound monoclonal antibody, and ${ }^{125} \mathrm{I}$-protein $\mathrm{A}$ $(\sim 10 \mu \mathrm{Ci} / 100 \mathrm{ml}$; Amersham, Arlington Heights, Ill.) was used to detect the bound rabbit immunoglobulin. BSA (3\%) was used to reduce nonspecific binding. Bound ${ }^{125}$ I was 
visualized on autoradiograms, and the relative amounts of EGFR and ErbB proteins were quantitated by computerassisted image analysis, using the software program IM 100 Densitometry (Microscience, Seattle, Wash.).

\section{RESULTS}

Choice of reaction conditions and exogenous substrate. To carry out comparative kinetic analyses on ErbB and chEGFR proteins, pilot reactions were performed to identify conditions that would give reproducible activity for exogenous substrates. These pilot tests revealed good activity for the exogenous substrate TK6 but very poor activity for enolase and a Src substrate peptide (RRLIEDAEYAARG). TK6 was therefore used in further studies. TK6 contains the autophosphorylation sites of the human EGFR and represents a homolog of the sites that undergo autophosphorylation in EGFR and ErbB proteins (14). In initial experiments using millimolar levels of $\mathrm{Mg}^{2+}$, no reproducible activity for TK6 was observed. In contrast, experiments using $15 \mathrm{mM}$ $\mathrm{Mn}^{2+}$ demonstrated reproducible tyrosine phosphorylation of TK6. Other ligand-domain-truncated forms of the EGFR have also shown a strong preference for $\mathrm{Mn}^{2+}$ over $\mathrm{Mg}^{2+}$ $(13,29)$. On the basis of these pilot tests, detailed studies were conducted under physiological salt conditions $(150 \mathrm{mM}$ $\mathrm{NaCl}$ ), using TK6 as the exogenous substrate and $15 \mathrm{mM}$ $\mathrm{Mn}^{2+}$ as the divalent cation.

Autophosphorylation activity of the chEGFR and ErbB proteins. To establish the time course and specificity of autophosphorylation, immune complexes were prepared and in vitro kinase assays were examined for autophosphorylation activity with time of incubation at $25^{\circ} \mathrm{C}$ (Fig. 2). Autophosphorylation of the chEGFR (Fig. 2A) was linear for at least $4 \mathrm{~min}$, whereas autophosphorylation of the AEV-5005 ErbB was linear for approximately 2 min (Fig. 2B). Evidence that the phosphorylation activity was a tyrosine protein kinase was obtained by incubating protein blots of kinase reactions with the antiphosphotyrosine antibody PY20. These blots revealed a more than 50 -fold increase of phosphotyrosine in chEGFR and ErbB proteins during kinase reactions (data not shown). ${ }^{32} \mathrm{P}$-labeled reaction products were also analyzed for phosphoamino acid content. These analyses revealed phosphotyrosine and not phosphoserine or phosphothreonine (data not shown). On the basis of these results, further studies on autophosphorylation were carried out for $70 \mathrm{~s}$ at $25^{\circ} \mathrm{C}$, and all incorporated ${ }^{32} \mathrm{P}$ counts were assumed to represent phosphorylation on tyrosine.

The apparent concentration of ATP required for halfmaximal rates of autophosphorylation $\left[K_{m}(\mathrm{app})\right]$ and the relative $V_{\max }(\mathrm{app})$ of the chEGFR and ErbB kinases (AEV5005 and AAV-5005) were next determined (Table 1). The AEV-H protein was not included in this study because of its C-terminal truncation that includes one of the major sites of autophosphorylation (Fig. 1). ATP concentrations of 1 to 50 $\mu \mathrm{M}$ (s.a., $6.4 \mu \mathrm{Ci} / \mathrm{nmol}$ ) were used in reactions. Kinase assays on the chEGFR were carried out in the absence of ligand. The chEGFR from NIH 3 T3 cells and from CEF and the two tested ErbB proteins had similar $K_{m}$ (app) values. These values were in good agreement with previously published values for immune complex kinase assays for the EGFR and ErbB kinases $(12,24)$. In contrast to the similarity of the ATP requirements, the relative $V_{\max }$ for autophosphorylation were distinctly higher for the ErbB than the chEGFR kinases: the ErbB of AEV-5005 had at least a threefold-higher and the ErbB of AAV-5005 had at least a sevenfold-higher autophosphorylation activity than did the

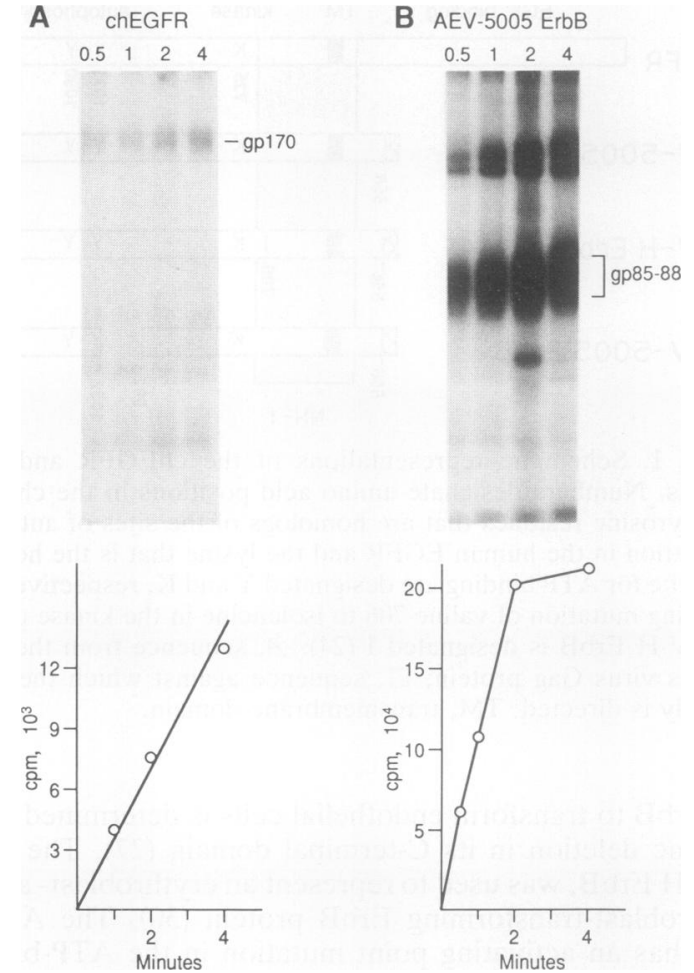

FIG. 2. Time course of autophosphorylation. Autoradiograms as well as graphic representations are presented for NN-1 immunoprecipitates of the chEGFR (NIH 3T3) (A) and the ErbB of AEV-5005 (B). Designations above the lanes indicate the times of reaction in minutes. Designations on the sides indicate the positions of the chEGFR (gp170) and ErbB (gp85-88). For details on conditions, see Materials and Methods.

chEGFR. This increased maximum velocity was consistent with the time course of autophosphorylation reactions that had revealed autophosphorylation of ErbB being linear over a more limited time span than autophosphorylation of the chEGFR (Fig. 2).

Phosphorylation activity of the chEGFR and ErbB proteins for the exogenous substrate TK6. As the first step to elucidating phosphorylation activity for an exogenous substrate, immunoprecipitates of the chEGFR and the AEV-5005 ErbB were prepared and the linearity with time of kinase activity for TK6 was determined (Fig. 3). These assays revealed a linear incorporation of ${ }^{32} \mathrm{P}$ on the $54-\mathrm{kDa}$ TK6 protein for at

TABLE 1. Autophosphorylation activities of the chEGFR and ErbB proteins ${ }^{a}$

\begin{tabular}{llr}
\hline \multicolumn{1}{c}{ Protein } & \multicolumn{1}{c}{$\begin{array}{c}K_{m} \text { (app) for } \\
\text { ATP }(\mu \mathrm{M})\end{array}$} & $\begin{array}{c}\text { Relative } V_{\max } \\
(\mathrm{fmol} / \mathrm{min})\end{array}$ \\
\hline chEGFR (NIH 3T3) & $6.4 \pm 2.5$ & $21.5 \pm 2.5$ \\
chEGFR (CEF) & $6.0 \pm 1$ & $15.4 \pm 1.0$ \\
AEV-5005 ErbB & $3.3 \pm 0.4$ & $61.5 \pm 1.2$ \\
AAV-5005 ErbB & $6.2 \pm 1$ & $153.9 \pm 6.2$ \\
\hline
\end{tabular}

a Immune complex kinase assays were carried out with the indicated chEGFR or ErbB proteins in the presence of 1 to $125 \mu \mathrm{M}$ ATP (s.a., 6.4 $\mu \mathrm{Ci} / \mathrm{nmol}$ ). Relative $V_{\max }$ values were calculated by using data obtained on protein blots to normalize the amounts of the ErbB or EGFR proteins to the amount of the EGFR in the chEGFR (NIH 3T3) samples. These normalizations reduced the $V_{\max }(\mathrm{app})$ values obtained for the ErbB proteins by two- to fourfold. 
A
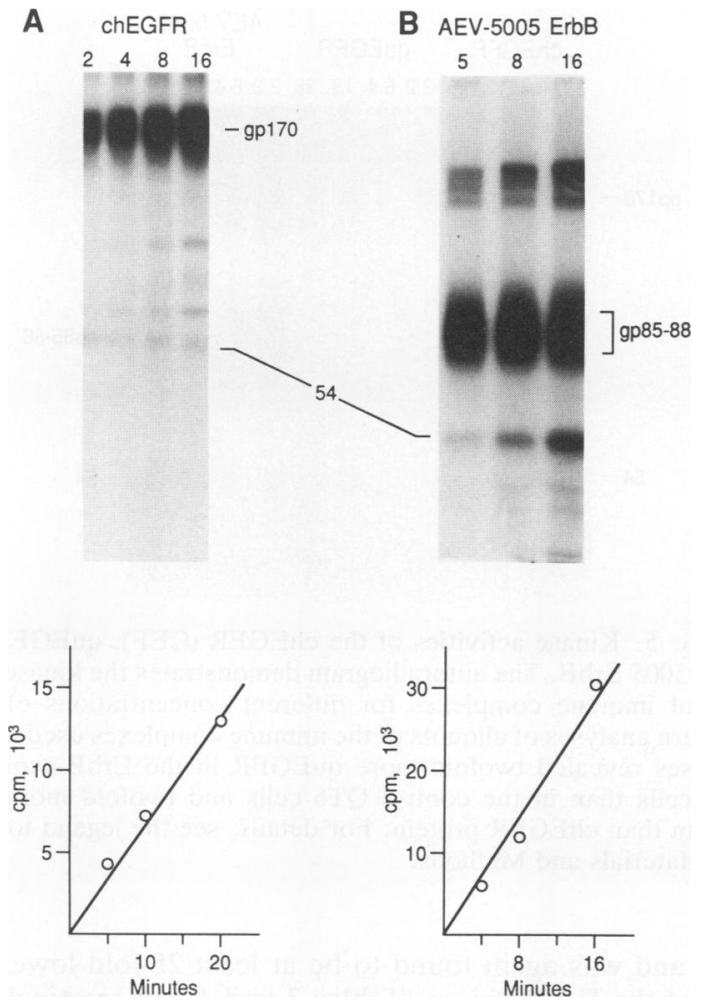

FIG. 3. Time course of TK6 phosphorylation. Autoradiograms as well as graphic representations are presented for NN-1 immunoprecipitates of the chEGFR (NIH 3T3) (A) and the ErbB of AEV-5005 (B). Designations above the lanes indicate the times of reaction in minutes. Designations on the sides indicate the positions of the chEGFR (gp170), ErbB (gp85-88) and TK6 (54 kDa [54]). For details on conditions, see Materials and Methods; $7.5 \mu \mathrm{M}$ TK6 was used in the reactions.

least 16 to $20 \mathrm{~min}$. On the basis of these experiments, further assays on the phosphorylation activity of the tyrosine kinases for the TK6 substrate were done with a 10-min incubation at $25^{\circ} \mathrm{C}$.

The $K_{m}$ (app) for ATP during the phosphorylation of an exogenous substrate was determined by using $7.5 \mu \mathrm{M}$ TK6. In experiments in which the concentration of ATP was varied from 1 to $60 \mu \mathrm{M}$, the $K_{m}$ (app) for ATP was 20 to 34 $\mu \mathrm{M}$ (Table 2). To determine the relative $V_{\max }($ app) of these reactions, aliquots of the immune complexes were saved and analyzed on protein blots for the relative amounts of chEGFR and ErbB proteins. Normalization of the $V_{\max }($ app)

TABLE 2. Effects of ATP concentration on phosphorylation of the TK6 substrate by chEGFR and ErbB proteins ${ }^{a}$

\begin{tabular}{lcc}
\hline \multicolumn{1}{c}{ Protein } & $\begin{array}{c}K_{\mathrm{m}} \text { (app) for } \\
\text { ATP }(\mu \mathrm{M})\end{array}$ & $\begin{array}{c}\text { Relative } V_{\max }(\text { app }) \\
(\mathrm{fmol} / \min )\end{array}$ \\
\hline chEGFR (NIH 3T3) & $33.8 \pm 4.7$ & $3.4 \pm 0.3$ \\
AEV-5005 ErbB & $26.1 \pm 3.9$ & $6.8 \pm 0.3$ \\
AAV-5005 ErbB & $20.1 \pm 2.5$ & $6.8 \pm 0.3$ \\
AEV-H ErbB & $30.1 \pm 3.1$ & $5.1 \pm 0.2$ \\
\hline
\end{tabular}

${ }^{a}$ Immune complex kinase assays were carried out with the chEGFR (NIH 3T3) or ErbB proteins in the presence of $7.5 \mu \mathrm{M}$ TK6 and 1 to $50 \mu \mathrm{M}$ ATP (s.a., $13.3 \mu \mathrm{Ci} / \mathrm{nmol}$ ). The $V_{\max }(\mathrm{app})$ values for the ErbB proteins were divided by values ranging from 2 to 3 to obtain values relative to that of the chEGFR (NIH 3T3).
TABLE 3. Effects of substrate TK6 concentration on phosphorylation by chEGFR (NIH 3T3) and ErbB proteins ${ }^{a}$

\begin{tabular}{lcc}
\hline \multicolumn{1}{c}{ Protein } & $\begin{array}{c}K_{m}(\text { app }) \text { for } \\
\text { TK6 }(\mu \mathrm{M})\end{array}$ & $\begin{array}{c}\text { Relative } V_{\max } \text { (app) } \\
\text { (fmol/min) }\end{array}$ \\
\hline chEGFR (NIH 3T3) & $0.5 \pm 0.25$ & $0.9 \pm 0.07$ \\
AEV-5005 ErbB & $56 \pm 19$ & $25 \pm 5$ \\
AAV-5005 ErbB & $20 \pm 5$ & $27 \pm 2$ \\
AEV-H ErbB & $48 \pm 18$ & $30 \pm 7$ \\
\hline
\end{tabular}

${ }^{a}$ Immune complex kinase assays were carried out with the indicated chEGFR or ErbB proteins in the presence of TK6 $(1.6$ to $26 \mu \mathrm{M})$ and $50 \mu \mathrm{M}$ ATP (s.a., $10 \mu \mathrm{Ci} / \mathrm{nmol}$ ). The $V_{\max }(\mathrm{app})$ values for the ErbB proteins were divided by values ranging from 2 to 3 to obtain values relative to that of the chEGFR (NIH 3T3).

for the relative levels of enzyme proteins revealed that the relative $V_{\max }(\mathrm{app})$ values for the three tested ErbB proteins were about two times higher than that for the chEGFR (NIH 3T3) (Table 2).

The $K_{m}$ (app) for TK6 as well as the relative $V_{\max }$ (app) for TK6 were next determined (Table 3). For these experiments, immune complex kinase assays were carried out in the presence of $50 \mu \mathrm{M}$ ATP and concentrations of TK6 ranging from 1.6 to $26 \mu \mathrm{M}$. The relative amounts of EGFR and ErbB proteins in reaction mixes were quantitated by protein blot analyses. In contrast to the studies on ATP requirement, in which autoradiograms of SDS-PAGE-fractionated kinase reactions revealed overall similar activities for each of the kinases, the autoradiograms of the reactions testing TK6 requirements revealed easily visualized differences between the tyrosine kinase activities of the chEGFR and ErbB proteins. Figure 4A shows an example of these data for the chEGFR and AEV-5005 ErbB proteins. Whereas the activity of the chEGFR was not obviously increasing at concentrations of TK6 above $3.2 \mu \mathrm{M}$, the activity of the ErbB kinase was still increasing at a concentration of $26 \mu \mathrm{M}$. The maximum velocity of the ErbB kinase was also substantially greater than that of the chEGFR, with similar levels of kinase proteins resulting in just detectable levels of TK6 phosphorylation by the chEGFR and near-overexposed levels of phosphorylation of TK6 by ErbB (Fig. 4A and B).

The kinetic parameters for the experiment in Fig. 4 were calculated by using a curve-fitting program for the MichaelisMenten equation. The $K_{m}$ (app) for TK6 for the chEGFR was $0.5 \mu \mathrm{M}$ (Table 3). In contrast the $K_{m}(\mathrm{app})$ for TK6 for each of the three tested ErbB proteins was $>20 \mu \mathrm{M}$ (Table 3). Quantitative determination of relative $V_{\max }(\operatorname{app})$ also revealed differences, with the ErbB proteins having relative $V_{\text {max }}$ (app) values that were at least 25 times higher than that of the chEGFR (NIH 3T3). Among the ErbB proteins, all had similar ATP requirements and similar relative $V_{\max }$ (app) values (Table 3 ).

Because of the large difference in $V_{\text {max }}$ (app) between the chEGFR (NIH 3T3) and the quail cell-expressed ErbB proteins, the $V_{\max }(\mathrm{app})$ and $K_{m}(\mathrm{app})$ for TK6 of the chEGFR (CEF) were analyzed to determine whether the kinetic properties of this naturally occurring receptor were similar to those of the expressed chEGFR. Also, as TK6 phosphorylation in the ErbB immune complexes could reflect the sum of the activities of ErbB and coprecipitated quEGFR proteins (note the presence of autophosphorylation of the quEGFR in Fig. 4), the activity of the quEGFR for TK6 was determined in parallel so that the level of TK6 phosphorylation in ErbB immune complexes could be corrected for the activity of coprecipitated quEGFR protein. Visualization of 
A
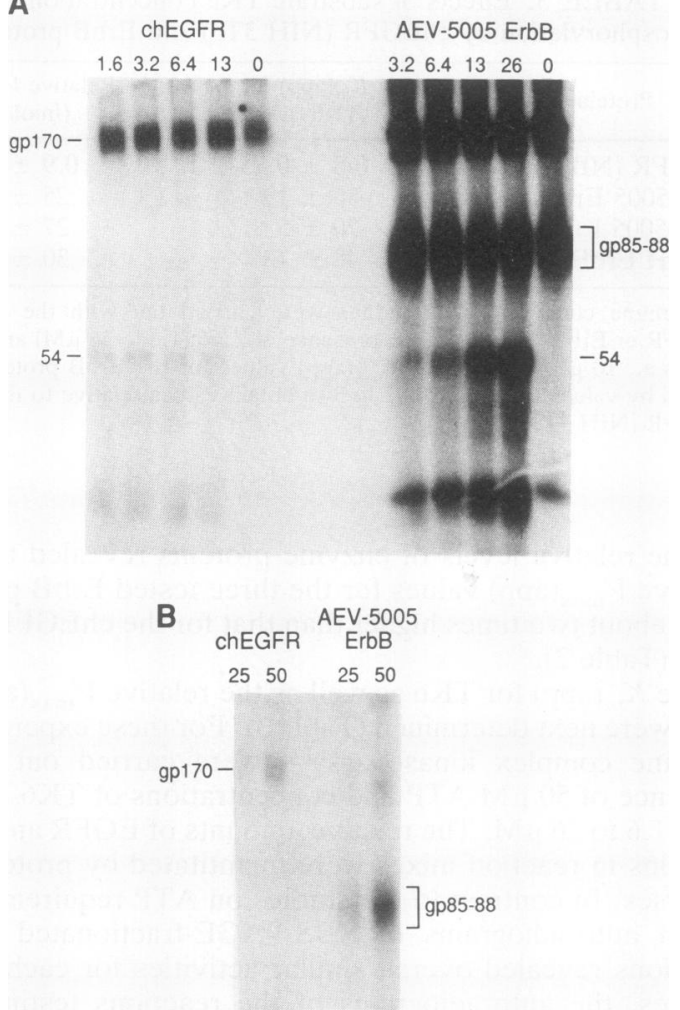

FIG. 4. Tyrosine kinase activities for TK6 of the chEGFR (NIH 3T3) and AEV-5005 ErbB. (A) Autoradiogram demonstrating the kinase activities of immunoprecipitated chEGFR and AEV-5005 ErbB proteins for different concentrations of TK6. Designations above the lanes indicate the concentrations (micromolar) of TK6; 50 $\mu \mathrm{M}$ ATP (s.a., $10 \mu \mathrm{Ci} / \mathrm{nmol}$ ) was used in the reactions. (B) Autoradiogram of a Western blot quantitating the relative amounts of chEGFR and ErbB in kinase reactions. The same amount of immunoprecipitate used for each kinase reaction was boiled in 100 $\mu l$ of Laemmli sample buffer. Designations above the lanes indicate the amounts (microliters) of sample analyzed. Designations on sides indicate the chEGFR (gp170), ErbB (gp85-88), and TK6 (54 kDa [54]). For experimental details, see Materials and Methods.

autoradiograms of this experiment again revealed the difference in $K_{m}$ for TK6 of the chEGFR and ErbB kinases (Fig. 5). However, comparison of the relative rates of autophosphorylation and TK6 phosphorylation indicated that the two chEGFRs differed in their relative activities for autophosphorylation and TK6 phosphorylation (Fig. 4A and 5). Whereas the chEGFR (CEF) had comparable activities for TK6 and autophosphorylation, the chEGFR (NIH 3T3) had much lower kinase activity for TK6 than for autophosphorylation. The autoradiograms also revealed much higher levels of autophosphorylation of the quEGFR in the immune complexes from the ErbB-expressing QT6 cells than in the immune complexes from control QT6 cells (Fig. 5). Western blot analysis of this experiment revealed that this difference correlated with the relative amounts of the quEGFR protein in assays.

Table 4 summarizes the kinetic values calculated from the experiment in Fig. 5. The calculated kinetic values for ErbB are presented both with and without corrections for the estimated level of TK6 phosphorylation by the quEGFR. The $K_{m}$ (app) for TK6 for the chEGFR (CEF) was very similar to that previously obtained for the chEGFR (NIH

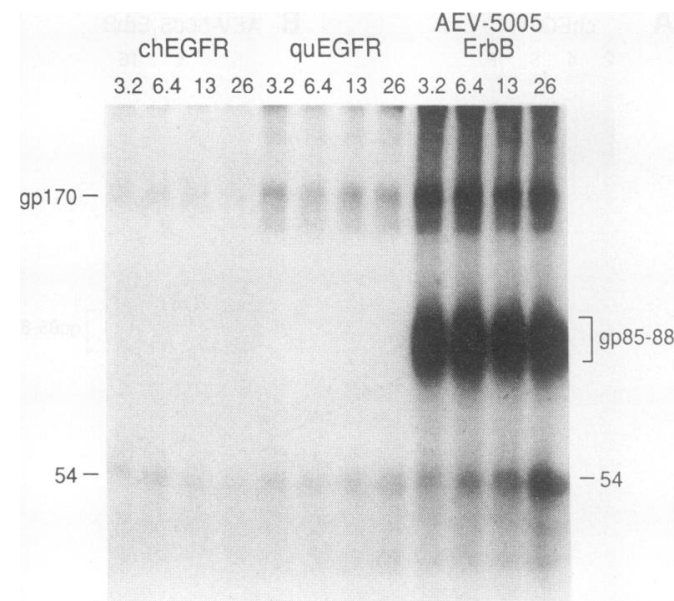

FIG. 5. Kinase activities of the chEGFR (CEF), quEGFR, and AEV-5005 ErbB. The autoradiogram demonstrates the kinase activities of immune complexes for different concentrations of TK6. Western analyses of aliquots of the immune complexes used in these analyses revealed twofold more quEGFR in the ErbB-expressing QT6 cells than in the control QT6 cells and twofold more ErbB protein than chEGFR protein. For details, see the legend to Fig. 4 and Materials and Methods.

3T3) and was again found to be at least 25-fold lower than that of the ErbB kinase (Tables 3 and 4). Interestingly, the $V_{\max }(\mathrm{app})$ of the chEGFR (CEF) was much more similar to that of the ErbB kinase than was the $V_{\max }$ (app) of the chEGFR (NIH 3T3), being only about 2-fold rather than 25-fold lower than that of ErbB (Tables 3 and 4). This twofold difference was maintained when the data for ErbB were corrected for the amount of TK6 phosphorylation by the quEGFR.

\section{DISCUSSION}

Multiple differences in the kinetics of the tyrosine kinase activities of chEGFR and ErbB proteins. (i) Activation of kinase activity. Our kinetic analyses suggest that truncation of the ligand-binding domain of the chEGFR increases the kinase activity of the ErbB region of the receptor. This was

TABLE 4. Effects of substrate TK6 concentration on phosphorylation by chEGFR (CEF) and AEV-5005 ErbB proteins ${ }^{a}$

\begin{tabular}{lcc}
\hline \multicolumn{1}{c}{ Protein } & $\begin{array}{c}K_{m}(\text { app }) \text { for } \\
\text { TK6 }(\mu \mathrm{M})\end{array}$ & $\begin{array}{c}\text { Relative } V_{\max }(\text { app }) \\
(\mathrm{fmol} / \min )\end{array}$ \\
\hline chEGFR (CEF) & $0.7 \pm 0.24$ & $1.8 \pm 0.07$ \\
AEV-5005 ErbB & $27 \pm 16$ & $5.8 \pm 2.0$ \\
AEV-5005 ErbB & $18 \pm 2$ & $3.0 \pm 0.02$ \\
\hline
\end{tabular}

${ }^{a}$ Immune complex kinase assays were carried out with the indicated proteins in the presence of TK6 $(3.2$ to $26 \mu \mathrm{M})$ and $50 \mu \mathrm{M}$ ATP (s.a., 10 $\mu \mathrm{Ci} / \mathrm{nmol}$ ). The $V_{\max }(\mathrm{app})$ for ErbB was divided by 2 to obtain values relative to that of the chEGFR.

${ }^{b}$ Data have been corrected for the activity of the quEGFR as well as normalized for the relative amounts of chEGFR and ErbB proteins. The correction for the quEGFR activity was done by (i) determining the activity of the quEGFR for TK6, (ii) multiplying this value by 2 to normalize for the relative levels of the quEGFR in the ErbB-expressing quail cells, and (iii) subtracting the normalized value from the level of TK6 phosphorylation in the ErbB samples. The correction for TK6 phosphoryaltion by the quEGFR represented about $30 \%$ of the amount of TK6 phosphorylation in the uncorrected ErbB samples. 
evidenced by ErbB proteins having at least 3-fold-higher relative $V_{\max }(\mathrm{app})$ for autophosphorylation (Table 1 ) and $\sim 2$-fold-higher relative $V_{\max }$ (app) for the phosphorylation of an exogenous substrate (TK6) (Table 2). These increases in $V_{\max }$ were not accompanied by changes in the apparent $K_{m}$ for ATP for autophosphorylation (Table 1) or the phosphorylation of an exogenous substrate (Table 2). Thus the ErbB proteins appear to be activated forms of the EGFR for autophosphorylation as well as the phosphorylation of an exogenous substrate.

(ii) Lower catalytic efficiency for an exogenous substrate. Truncation of the ligand-binding domain of the EGFR had complex consequences for the activity of the ErbB region of the receptor for the exogenous substrate TK6 (Tables 3 and 4). In EGF-induced activation of the receptor, the velocity of kinase reactions for peptide substrates increases without marked changes in peptide requirements (6). In contrast, the tested ErbB proteins had both increased relative $V_{\max }$ (app) and increased $K_{m}($ app) for the exogenous substrate TK6 (Tables 3 and 4). One estimate of the catalytic efficiency of an enzyme can be calculated as $V_{\max } / K_{m}$. The ratios of the $V_{\max }(\mathrm{app})$ to the $K_{m}$ (app) for the naturally occurring CEF and AEV-5005 ErbB (Table 4) would suggest that the chEGFR kinase has a 10-fold-greater catalytic efficiency for TK6 than does the ErbB kinase. However, ErbB proteins do have the potential for having higher kinase activities for TK6 than does the chEGFR if sufficient levels of TK6 are present (Tables 3 and 4; Fig. 4 and 5). Such high concentrations would be likely to have physiological relevance only for substrates that bind to the C-terminal domain of the receptor (such as SH2-domain-containing proteins [1]). The local apparent concentration of such substrates could be quite high. Indeed, the increased autophosphorylation activity of ErbB may be an example of the effect of a tethered substrate (Table 1).

(iii) Cell type dependence of activity. Interestingly, the relative $V_{\text {max }}\left(\right.$ app) but not the $K_{m}$ (app) for TK6 was affected by the cell type expressing the chEGFR (Fig. 4 and 5; Tables 3 and 4). This was demonstrated by the chEGFR (CEF) having a $V_{\max }(\mathrm{app})$ for TK6 that was much more similar to that of ErbB than was that of the chEGFR (NIH 3T3). This strong effect of the cell of origin on the $V_{\text {max }}(\mathrm{app})$ warrants further investigation. This effect could reflect a modification of the receptor in NIH 3T3 cells that reduced the velocity of the receptor kinase for exogenous substrates.

Autophosphorylation activity and broadening of the disease potential of ErbB. Three ErbB proteins with distinct disease potentials were compared for kinase activities. No differences were found in the activities of these ErbB kinases for the exogenous substrate TK6 (Table 3 ). In contrast, analyses for autophosphorylation activity revealed a 2.5-fold increase in the $V_{\max }(\mathrm{app})$ for the AAV-5005 ErbB relative to that of the AEV-5005 ErbB (Table 1). The AAV-5005 ErbB causes erythroblastosis and angiosarcoma, whereas the AEV-5005 ErbB causes only erythroblastosis (27). The correlation of an increase in autophosphorylation activity with a mutation that broadens oncogenic potential (Fig. 1) is consistent with in vivo studies showing increased levels of phosphotyrosine on ErbB proteins with certain activating mutations $(24,25)$. One role for autophosphorylation of ErbB in the broadening of transformation potential could be increased binding of signalling molecules with $\mathrm{SH} 2$ domains to the phosphorylated forms of ErbB $(1,28)$.

Conditions used for kinetic analyses. The conclusions drawn from our studies apply to our specific set of experimental conditions. These conditions impose certain limits on the interpretation of the results. (i) Assays were performed with immune complexes. The NN-1 antiserum used for immune complex kinase assays was raised against an expressed protein that extended into the kinase domain (Fig. 1). This antiserum could interfere with kinase activity and affect the determined kinetic parameters. (ii) All ErbB assays were carried out in the presence of the quEGFR, with oflly the data in Table 4 being corrected for the apparent activity of the quEGFR for the exogenous substrate. (iii) $\mathrm{A}$ nonphysiological level of a divalent cation (15 $\mathrm{mM} \mathrm{Mn}^{2+}$ ) was used in reaction mixtures. This divalent cation activates the kinase activity of the EGFR as well as the kinase activity of fragments of the EGFR $(13,29)$. (iv) None of the assays for EGFR kinase activity included ligand. (v) The affinity of the monoclonal antibody used to evaluate relative levels of chicken and quail proteins could have affected the accuracy of the estimated values for $V_{\text {max }}(\mathrm{app})$. (vi) Our assays included analyses of the kinetics for only one exogenous substrate, TK6. Thus, our results apply for this substrate and cannot be generalized to other substrates without determining the kinetics of reactions for these substrates.

Despite these caveats, this study is the first to compare the kinetics of the activity of the chEGFR and ErbB kinases. The results indicate that under a given set of conditions, the ErbB kinase differs from the chEGFR kinase in its $V_{\max }$ (app) for autophosphorylation, its relative $V_{\max }(\mathrm{app})$ for an exogenous substrate, and its $K_{m}$ (app) for an exogenous substrate. We suggest that these marked alterations in the kinetics of kinase activity will contribute to the transforming potential of the ErbB oncogene.

\section{ACKNOWLEDGMENTS}

We thank S. Kawaii for the provision of pAE7.7, I. Lax and J. Schlessinger for the gift of NIH 3T3 cells expressing the chEGFR, R. Cerione for the gift of pGEX-TK6, M. Hayman for monoclonal antibody 20.3.6, and R. Kris for the RK-2 antibody that was used during the establishment of conditions for kinase assays. We are indebted to S. Tracy for ErbB-expressing QT6 cells and thank D. Gamett for critical comments on the manuscript.

This work was supported by Public Health Service grant RO1 CA 27223 and by PO1 CA 39240.

\section{REFERENCES}

1. Anderson, D., C. A. Koch, L. Grey, C. Ellis, M. F. Moran, and T. Pawson. 1990. Binding of SH2 domains to phospholipase C 1, GAP, and Src to activated growth factor receptors. Science 250:979-982.

2. Beug, H., M. J. Hayman, M. B. Raines, H. J. Kung, and B. Vennstrom. 1986. Rous-associated virus 1-induced erythroleukemic cells exhibit a weakly transformed phenotype in vitro and release c-erbB containing retroviruses unable to transform fibroblasts. J. Virol. 57:1127-1138.

3. Decker, S. J. 1985. Phosphorylation of the erbB gene product from an avian erythroblastosis virus-transformed chick fibroblast cell line. J. Biol. Chem. 260:2003-2006.

4. Deickmann, C. L., and A. Tzagoloff. 1985. Assembly of the mitochondrial membrane system. J. Biol. Chem. 260:1513-1520.

5. Englebreth-Holm, J., and A. Rothe-Meyer. 1932. Bericht uber neue Erfahrungen mit einem stamm huhner erythroleukose. Acta. Pathol. Microbiol. Scand. 9:293-312.

6. Erneux, C., S. Cohen, and D. L. Garbers. 1983. The kinetics of tyrosine phosphorylation by the purified epidermal growth factor receptor kinase of A-431 cells. J. Biol. Chem. 258:41374142.

7. Gamett, D. C., S. E. Tracy, and H. L. Robinson. 1986. Differences in sequences encoding the carboxyl-terminal domain of the epidermal growth factor receptor correlate with differences in the disease potential of viral erbB genes. Proc. Natl. Acad. Sci. USA 83:6053-6057. 
8. Gilmore, T., J. E. DeClue, and G. S. Martin. 1985. Protein phosphorylation at tyrosine is induced by the v-erbB gene product in vivo and in vitro. Cell 40:609-618.

9. Hayman, M. J., G. Kitchener, J. Knight, J. McMahon, R. Watson, and H. Beug. 1986. Analysis of the autophosphorylation activity of transformation defective mutants of avian erythroblastosis virus. Virology 150:270-275.

10. Heimann, B., P. Beimling, E. Pfafi, H. Schaller, and K. Moelling. 1985. Analysis of a tyrosine-specific protein kinase activity associated with the retroviral erbB oncogene product. Exp. Cell Res. 161:199-208.

11. Hihara, H., H. Yamamoto, H. Shimohira, K. Arai, and T. Shimizu. 1983. Avian erythroblastosis virus isolated from chick erythroblastosis-induced by lymphatic-leukemia virus subgroup. A. J. Natl. Cancer Inst. 70:891-897.

12. Honegger, A., T. J. Dull, D. Szapary, A. Komoriya, R. Kris, A. Ullrich, and J. Schlessinger. 1988. Kinetic parameters of the protein tyrosine kinase activity of EGF-receptor mutants with individually altered autophosphorylation sites. EMBO J. 7:3053-3060.

13. Koland, J. G., and R. A. Cerione. 1990. Activation of the EGF receptor tyrosine kinase by divalent metal ions: comparison of the holoreceptor and isolated kinase domain properties. Biochim. Biophys. Acta 1052:489-498.

14. Koland, J. G., K. M. O'Brien, and R. A. Cerione. 1990. Expression of the epidermal growth factor receptor sequences as $E$. coli fusion protein: applications in the study of tyrosine kinase function. Biochem. Biophys. Res. Commun. 166:90-100.

15. Kris, R. M., I. Lax, W. Gullick, M. D. Waterfield, A. Ullrich, M. Fridkin, and J. Schlessinger. 1985. Antibodies against a synthetic peptide as a probe for the kinase activity of the avian EGF receptor and v-erbB protein. Cell 40:619-625.

16. Laemmli, U. K. 1970 . Cleavage of structural proteins during the assembly of the head of bacteriophage T4. Nature (London) 227:680-685

17. Lax, I., A. Johnson, R. Howk, J. Sap, F. Bellot, M. Winkler, A. Ullrich, B. Vennstrom, J. Schlessinger, and D. Givol. 1988. Chicken epidermal growth factor (EGF) receptor: cDNA cloning, expression in mouse cells, and differential binding of EGF and transforming growth factor alpha. Mol. Cell. Biol. 8:1970-1978.

18. Miles, B. D. M., and H. L. Robinson. 1985. High-frequency transduction of c-erbB in avian leukosis virus-induced erythroblastosis. J. Virol. 54:295-303.

19. Moscovici, C., M. G. Moscovici, H. Jimenez, M. Lai, M. Hayman, and P. K. Vogt. 1977. Continuous tissue culture cell lines derived from chemically induced tumors of Japanese quail. Cell 11:95-100.

20. Ng, M., and M. L. Privalsky. 1986. Structural domains of the avian erythroblastosis virus $e r b \mathrm{~B}$ protein required for fibroblast transformation: dissection by in-frame insertional mutagenesis. J. Virol. 58:542-553.

21. Pelley, R. J., N. J. Maihle, C. Boerkoel, H. K. Shu, T. H. Carter, C. Moscovici, and H. J. Kung. 1989. Disease tropism of c-erbB: effects of carboxy-terminal tyrosine and internal mutations on tissue specific transformation. Proc. Natl. Acad. Sci. USA 86:7164-7168.

22. Raines, M. A., N. J. Maihle, C. Moscovici, M. Moscovici, and H. J. Kung. 1988. Molecular characterization of three erbB transducing viruses generated during avian leukosis virus-induced erythroleukemia: extensive internal deletions near the kinase domain activate the fibrosarcoma- and hemangiomainducing potential of erbB. J. Virol. 62:2444-2452.

23. Sealy, L., M. L. Privalsky, G. Moscovici, C. Moscovici, and J. M. Bishop. 1983. Site-specific mutagenesis of avian erythroblastosis virus: $e r b$-B is required for oncogenicity. Virology 130:155-178.

24. Shu, H.-K. G., R. J. Pelley, H.-J. Kung. 1990. Tissue-specific transformation by epidermal growth factor receptor: a single point mutation within the ATP-binding pocket of the ErbB product increases its intrinsic kinase activity and activates its sarcomagenic potential. Proc. Natl. Acad. Sci. USA 87:91039107.

25. Shu, H.-K. G., R. J. Pelley, and H.-J. Kung. 1991. Dissecting the activating mutations in v-erbB of avian erythroblastosis strain R. J. Virol. 65:6173-6180.

26. Towbin, H., T. Staehelin, and J. Gordon. 1979. Electrophoretic transfer of proteins from polyacrylamide gels to nitrocellulose sheets: procedure and some applications. Proc. Natl. Acad. Sci. USA 76:4350-4354.

27. Tracy, S. E. 1988. Characterization of a deletion in erbB sequences associated with angiosarcoma. Ph.D. thesis. University of Massachusetts Medical School, Worcester.

28. Ulirich, A., and J. Schlessinger. 1990. Signal transduction by receptors with tyrosine kinase activity. Cell 61:203-212.

29. Wedergaertner, P. B., and G. N. Gill. 1989. Activation of the purified tyrosine kinase domain of the epidermal growth factor receptor. J. Biol. Chem. 264:11346-11353.

30. Yamamoto, T., T. Nishida, N. Miyajima, S. Kawai, T. Ooi, and K. Toyoshima. 1983. The erbB gene of avian erythroblastosis virus is a member of the $s r c$ gene family. Cell 35:71-78. 